\section{Extreme rainfall trends over the Mekong Delta under the impacts of climate change}

Extreme rainfall trends over the Mekong Delta

\author{
Seung Kyu LEE
}

Sustainable Management of Natural Resources and Environment Research Group, Faculty of Environment and Labour Safety,

Ton Duc Thang University, Vietnam, and

Truong An Dang

University of Science-HCMC, Vietnam National University Ho Chi Minh City, Ho Chi Minh City, Vietnam

\begin{abstract}
Purpose - This study aims to investigate aspects related to the changing trends of the rainfall extremes in the entire Mekong Delta in the period of 32 years (1984-2015) applying rainfall extreme indices. First, the homogeneity tests were applied to assess the quality of observed rainfall data series. The authors, then, investigated three rainfall indices including the number of very heavy rainfall days $20 \mathrm{~mm}$ (R20), number of days above $50 \mathrm{~mm}$ (R50) and number of days above $100 \mathrm{~mm}$ (R100) applying the Mann-Kendall test and Sen's slope estimate.
\end{abstract}

Design/methodology/approach - First, the homogeneity tests were applied to assess the quality of observed rainfall data series. The authors, then, investigated three rainfall indices including the number of very heavy rainfall days $20 \mathrm{~mm}$ (R20), number of days above $50 \mathrm{~mm}$ (R50) and number of days above $100 \mathrm{~mm}$ (R100) applying the Mann-Kendall test and Sen's slope estimate.

Findings - The results of R20 pointed out that an insignificant upward tendency was found in the coastal provinces, whereas an insignificant downward tendency was also recorded in the inland provinces. Regarding the number of R50, a similar trend to R20 was recorded with five stations slightly increased and five stations slightly decreased. For the number of R100, the results recorded an absence of significant trends over the entire study area. Approximately $58.5 \%$ of stations show a slightly decreasing trend, while $41.5 \%$ of the remaining stations recorded a slightly increasing trend.

Originality/value - For the number of R100, the results recorded an absence of the significant trends over the entire study area. Approximately $58.5 \%$ of stations show a slightly decreasing trend, while $41.5 \%$ of the remaining stations recorded a slightly increasing trend. Of note is the fact that the number of R100 occurred more frequently in the northern provinces, which means the northern region is facing a high risk of flooding.

Keywords Flooding, Non-parametric test, Rainfall extremes, Rainfall trend, Sen's slope

Paper type Research paper

(C) Seung Kyu LEE and Truong An Dang. Published by Emerald Publishing Limited. This article is published under the Creative Commons Attribution (CC BY 4.0) licence. Anyone may reproduce, distribute, translate and create derivative works of this article (for both commercial and noncommercial purposes), subject to full attribution to the original publication and authors. The full terms of this licence may be seen at http://creativecommons.org/licences/by/4.0/legalcode

The author(s) received no financial support for this research.

This paper forms part of special section "Climate change impacts and adaptations in arid and semi-arid regions", guest edited by Zhihua Zhang, Qiang Zhang and Muhammad Jawed Iqbal.
Received 12 April 2020 Revised 22 May 2020 1 June 2020 Accepted 2 June 2020 
IJCCSM

12,5

640

\section{Introduction}

In recent decades, climate change has significantly affected most regions of the world and it is considered to be a major topic in the 21st century (Lee and Dang, 2019b; Intergovernmental Panel on Climate Change [IPCC], 2012; Xu et al., 2015). The Intergovernmental Panel on Climate Change IPCC (2012) reported that climate change is one of the major causes of the rise of extreme weather indices in many regions of the world. According to Croitoru et al. (2013), the frequency of extreme weather events is rising due to global warming, especially extreme rainfall. They reported that extreme rainfall events (EREs) can cause negative effects on all aspects of life. Therefore, rainfall is one of the meteorological factors that has received the most attention, because EREs can have the negative impacts on several vital sectors of the economy, such as agriculture, infrastructure and transport (Attogouinon et al., 2017; Lee and Dang, 2018; Yazid and Humphries, 2007). In their study on extreme rainfall trends over Utah, Dos Santos et al. (2011) showed that regions and countries that economically depend on agriculture be affected by variations in rainfall. Indeed, studies on extreme rainfall trends are prominent in showing not only their previous evolution but also current and future trends. This can help in formulating strategies to mitigate the impacts of climate change.

Recognizing the importance of EREs for many aspects of life in the context of climate change in recent years, numerous studies have been devoted to trends in EREs on regional, national and global scales (Pingale et al., 2014; Lee and Dang, 2019b; Liu et al., 2015; Soro et al., 2016). Singh et al. (2013) conducted a study on changing trends in extreme seasonal rainfall events over continental America. They concluded that heavier rainfall events in the future will lead to more frequent wet and dry extremes in most regions of the Americas. Mondal and Mujumdar (2015) analysed changes in extreme rainfall characteristics in India, including the intensity, duration and frequency of excess rain over a high threshold. They reported that the varying nature of each extreme rainfall characteristic has led to the necessity of a comprehensive framework for assessing the resulting risks of rainfall-induced flooding. Liu et al. (2015) studied EREs to understand flood risks in detail for the Jakarta region of Indonesia. They reported that the return period of the extreme rainfall event on February 2007 in Jakarta was over 300 years for a three-day duration at Halim station. Wu et al. (2016) studied extreme summer rainfall over East Asia. They reported that the EREs showed high complexity from one region to another. Meanwhile, Daksiya et al. (2017) studied annual and seasonal rainfall extremes for a Southeast Asian region under current and future climate conditions. They found significant changes in annual maximum rainfall, with an average increase in daily rainfall as high as $20 \%$ in the 100 -year return period. Attogouinon et al. (2017) analysed trends in extreme rainfall based on daily rainfall data for the Upper Ouémé valley in Benin over the period 1951-2014 using the non-parametric Mann-Kendall test. Their results revealed that only $30 \%$ of the stations experienced decreasing trends for the number of heavy rainfall days and daily maximum rainfall. Lee and Dang (2019) conducted a study on spatio-temporal change trends in rainfall characteristics over the MRD in the recent decades. The results showed that a tendency to decrease in frequency of rainfall is recorded, while a tendency to increase in the spatial distribution is found. Dang (2019) studied maximum rainfall trends in the Long Xuyen Quadrangle Area, Vietnam, over three past decades. The results carried out that approximately of 80 percent of the study area was occurred a slight downward trend of the R20 index. A similar to the R20 index was recorded for the R50 index. According to Adeniran et al. (2010), the growth and development stages of crops mainly depend on rainfall factors. They concluded that too little rainfall will negatively influence agricultural production, while high levels of rainfall also have detrimental effects on crop yields. 
The Mekong Delta is one of the largest agricultural production areas in Vietnam and is facing an increasing trend in waterlogging and flooding in recent years due to EREs. According to our understanding, no study on rainfall extremes has been conducted in the Mekong Delta. It is, therefore, necessary to study extreme weather events in potential crop growing areas to provide early warnings and minimise their negative effects. Thus, this research aimed to assess extreme rainfall events in the Mekong Delta Area by applying the Mann-Kendall test and Sen's slope estimator.

\section{Materials and method}

\subsection{Study area}

The Mekong Delta, located at $8^{\circ} 34^{\prime}-11^{\circ} 10^{\prime} \mathrm{N}$ latitude and $104^{\circ} 25^{\prime}-106^{\circ} 48^{\prime} \mathrm{E}$ longitude, has a total area of land for agriculture production of approximately 1,690,000 hectares (Figure 1) and a population of approximately 21.49 million people in 2019. It is a coastal delta in the south of Vietnam and belongs to the lower Mekong River (Vu et al., 2018; Lee and Dang, 2019a). The study area is strongly influenced by flows from the upper Mekong River in the flood season and by tide currents that cause saline intrusion from the east and, west seas in the dry season due to low terrain, with elevations ranging from $0.3-2.0 \mathrm{~m}$ above mean sea level [Mekong Delta Plan (MDP), 2013; Vu et al., 2018]. Therefore, the Mekong Delta is particularly sensitive and vulnerable to climate change, and the characteristics of rainfall vary across different seasons.

The study area is dominated by a tropical monsoon circulation, with two major monsoon seasons, the northeast and southwest, that alternately blow throughout the year [Food and Agriculture Organization (FAO), 2016; Lee and Dang, 2019a; Mekong Delta Plan (MDP), 2013].
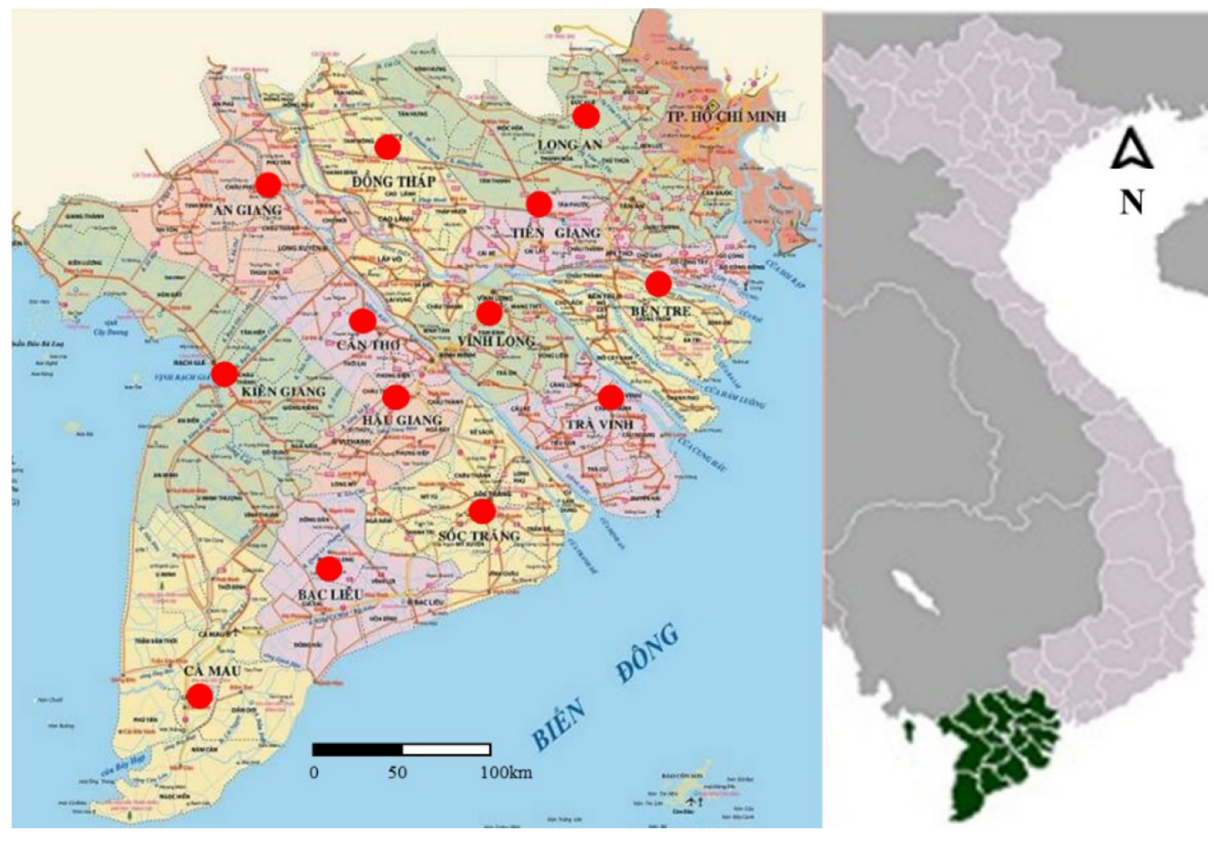

Extreme rainfall trends over the Mekong Delta

641

Source: Lee and Dang (2019a)

Figure 1. Study area with weather stations marked by the red circles 
IJCCSM

12,5

642

The southwest monsoon often lasts from May to October, while the northeast monsoon lasts from November to April [Asia-Pacific Network, 2010; Lee and Dang, 2019a; Mekong Delta Plan (MDP), 2013]. In the Mekong Delta Area, the rainy season often coincides with the southwest monsoon and is characterised by being hot, very humid with average annual humidity of approximately $89 \%$, and, having abundant rainfall, with an intensity of approximately $85 \%$ of annual rainfall (Figure 2). The dry season coincides with the northeast monsoon and is dominated by dry, and, hot conditions with less rainfall [Asia-Pacific Network, 2010; Food and Agriculture Organization (FAO), 2016]. The eastern and western coastal provinces have a high concentration of rainfall, with an annual mean rainfall of approximately $1,800-2,300 \mathrm{~mm}$. The inland provinces have annual mean rainfall ranging from $1,350 \mathrm{~mm}$ to 1,680 $\mathrm{mm}$ (Table 1).

\subsection{Data description}

To perform this research, the daily rainfall data series at 46 rainfall gauge stations belonging to the Mekong Delta Area for the period 1984-2015 were collected from the Southern Regional Hydro-meteorological Centre of Vietnam (SRHCV) to analyze extreme rainfall indices. The gauge stations lack synchronisation due to changing positions, so, we only selected 12 -gauge stations that represent 13 provinces belonging to the study area, as shown in Figure 1. To ensure the quality of the collected data series, rainfall data of the 12gauge stations were obtained based on the sufficient length and width of the observed data series to capture the fluctuations of rainfall. This ensured that the deviation between the gauge stations did not exceed $10 \%$.

\subsection{Extreme rainfall indices}

The World Meteorological Organization (WMO) recommends several ERIs for investigating changing trends in the spatial and temporal distributions at country, regional and world scales. The ERIs summarised in Table 2 have been widely applied (Attogouinon et al., 2017; Soro et al., 2016; Xu et al., 2015).

Rainfall indices namely the number of very heavy rainfall days $20 \mathrm{~mm}$ (R20), number of days above $50 \mathrm{~mm}$ (R50) and number of days above $100 \mathrm{~mm}$ (R100)) were adopted based on the preliminary analysis of the rainfall characteristics.

\subsection{Detecting extreme rainfall trends}

Numerous statistical methods, such as parametric and non-parametric tests have been used to detect monotonic trends in hydro-meteorology and environment problems (Attogouinon et al, 2017; Lee and Dang, 2019a; Xu et al, 2015). The Mann-Kendall test and Sen's slope estimator

Figure 2.

Monthly mean rainfall at gauge stations for the period 1984-2015

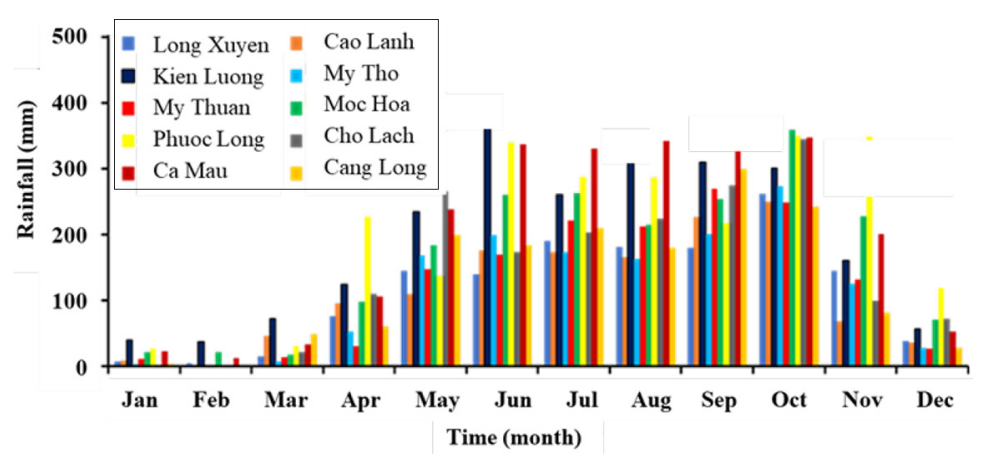


have been widely applied to determinate tendencies in rainfall characteristics (Attogouinon et al., 2017; Lee and Dang, 2019c; Jain and Kumar, 2012). One benefit of these tests is that they are non-parametric, very simple, do not require the assumption of normality, are robust against outliers and can handle missing values (Chandler and Scott, 2011; Moulai et al., 2013). Another advantage of applying the Mann-Kendall test is that it has low sensitivity to abrupt breaks due to inhomogeneous data series (Xu et al., 2015; Wani et al., 2013). The Mann-Kendall test is considered perfect if various points are tested in a single data series.

The Mann-Kendall test is defined by equation (1):

$$
S=\sum_{i=1}^{n-1} \sum_{j=i+1}^{n} \operatorname{Sgn}\left(X_{j}-X_{i}\right)
$$

With $\operatorname{Sgn}(. .$.$) is given by equation (2):$

\begin{tabular}{|c|c|c|c|c|c|c|c|}
\hline No. & Station & $\mathrm{AMR}(\mathrm{mm})$ & $\mathrm{SD}(\mathrm{mm})$ & Longitude (E) & Latitude (N) & Periods & \\
\hline 1 & Long Xuyen & 1362 & 81.77 & $105^{\circ} 25^{\prime} 13$ & $10^{\circ} 22 ' 21$ & 1978-2015 & \\
\hline 2 & My Tho & 1379 & 83.49 & $106^{\circ} 20^{\prime} 37$ & $10^{\circ} 22 ’ 35$ & $1978-2015$ & \\
\hline 3 & Cao Lanh & 1365 & 77.79 & $105^{\circ} 38^{\prime} 02$ & $10^{\circ} 27^{\prime} 17$ & $1984-2015$ & \\
\hline 4 & My Thuan & 1483 & 90.15 & $105^{\circ} 56^{\prime} 37$ & $10^{\circ} 14^{\prime} 49$ & 1978-2017 & \\
\hline 5 & Phuoc Long & 1884 & 109.99 & $105^{\circ} 45^{\prime} 22$ & $09^{\circ} 34^{\prime} 40$ & 1978-2015 & \\
\hline 6 & Kien Luong & 2087 & 118.67 & $104^{\circ} 38^{\prime} 07$ & $10^{\circ} 18^{\prime} 15$ & $1974-2018$ & . \\
\hline 7 & Ca Mau & 2328 & 132.68 & $105^{\circ} 07^{\prime} 35$ & $09^{\circ} 10^{\prime} 15$ & 1975-2018 & Annual mean rainfall \\
\hline 8 & Cang Long & 1535 & 89.75 & $106^{\circ} 13^{\prime} 42$ & $09^{\circ} 58^{\prime} 02$ & $1980-2015$ & (AMR) and standard \\
\hline 9 & Cho Lach & 1537 & 109.08 & $106^{\circ} 10^{\prime} 11$ & $10^{\circ} 14^{\prime} 27$ & $1979-2017$ & deviation (SD) at \\
\hline 10 & Moc Hoa & 1633 & 104.79 & $105^{\circ} 57^{\prime} 12$ & $10^{\circ} 44^{\prime} 51$ & $1978-2016$ & gauge stations \\
\hline
\end{tabular}

\begin{tabular}{|c|c|c|c|c|}
\hline Index & Indicator name & Definitions & Units & \\
\hline SDII & Simple daily intensity indices & $\begin{array}{l}\text { Annual total rainfall divided by the number of wet } \\
\text { days (defined as PRCP } \geq \text { D } 1.0 \mathrm{~mm} \text { ) in the year }\end{array}$ & mm day-1 & \\
\hline R10 & Number of heavy rainfall days & Annual count of days when $\mathrm{PRCP} \geq \mathrm{D} 10 \mathrm{~mm}$ & days & \\
\hline $\mathrm{R} 20$ & $\begin{array}{l}\text { Number of very heavy rainfall } \\
\text { days }\end{array}$ & Annual count of days when PRCP $\geq$ D $20 \mathrm{~mm}$ & days & \\
\hline R25 & $\begin{array}{l}\text { Number of days } \\
\text { above mm }\end{array}$ & Annual count of days when $\mathrm{PRCP} \geq \mathrm{D} 25 \mathrm{~mm}$ & days & \\
\hline $\mathrm{CDD}$ & Consecutive dry days & $\begin{array}{l}\text { Maximum number of consecutive days with } \\
\mathrm{RR} \leq 1 \mathrm{~mm}\end{array}$ & days & \\
\hline CWD & Consecutive wet days & $\begin{array}{l}\text { Maximum number of consecutive days with } \mathrm{RR} \geq \mathrm{D} \\
1 \mathrm{~mm}\end{array}$ & days & Table 2. \\
\hline R95p & Very wet days & Annual total PRCP when RR > 95th percentile & $\mathrm{mm}$ & List of extreme \\
\hline R99p & Extremely wet days & Annual total PRCP when RR > 99th percentile & $\mathrm{mm}$ & $\begin{array}{l}\text { List or extreme } \\
\text { rainfall indices }\end{array}$ \\
\hline \multicolumn{4}{|c|}{$\begin{array}{l}\text { Note: PRCP is the daily precipitation amount; RR is the daily precipitation amount on day } \\
\text { Source: } \mathrm{Xu} \text { et al. (2015) }\end{array}$} & $\begin{array}{r}\text { established by the } \\
\text { WMO }\end{array}$ \\
\hline
\end{tabular}


IJCCSM

12,5

$$
\operatorname{Sgn}\left(X_{j}-X_{i}\right)=\left\{\begin{array}{c}
+1 \text { if } x_{j}-x_{i}>0 \\
0 \text { if } x_{j}-x_{i}=0 \\
-1 \text { if } x_{j}-x_{i}<0
\end{array}\right.
$$

where $X_{j}$ and $X_{i}$ are the annual data series; $j$ and $i$ have the condition of $j>$ i. where if $n \geq 10$, the statistic sign $\mathrm{S}$ is considered a standard distribution, with the average value $(\mathrm{E})$ being defined by equation (3):

$$
\mathrm{E}[\mathrm{S}]=0
$$

and variance (Var) is given as in equation (4):

$$
\operatorname{Var}(\mathrm{S})=\frac{1}{18}\left[\mathrm{n}(\mathrm{n}-1)(2 \mathrm{n}+5)-\sum_{\mathrm{j}=1}^{\mathrm{m}} \mathrm{t}_{\mathrm{j}}\left(\mathrm{t}_{\mathrm{j}}-1\right)\left(2 \mathrm{t}_{\mathrm{j}}+5\right)\right]
$$

where $m$ is the number of the tied groups in the data series; $t_{j}$ is the number of ties to extent $j$.

The summation term in the numerator is used if the data series contain tied values. For the sample size $n>10$, the corresponding values of $S$ and $\operatorname{Var}(S)$ are calculated by the statistics of the standard test $\left(Z_{\mathrm{s}}\right)$. where $Z_{\mathrm{s}}$ is calculated by equation (5):

$$
Z_{\mathrm{S}}= \begin{cases}\frac{\mathrm{S}-1}{\sqrt{\operatorname{Var}(\mathrm{S})}} & \text { if } S>0 \\ 0 & \text { if } S=0 \\ \frac{\mathrm{S}-1}{\sqrt{\operatorname{Var}(\mathrm{S})}} & \text { if } S<0\end{cases}
$$

where $\mathrm{S}$ in equation (5) is defined by equation (6):

$$
\tau=\frac{\mathrm{S}}{\mathrm{D}}
$$

while $\mathrm{D}$ in equation (6) is calculated by equation (7):

$$
D=\left[\frac{1}{2} n(n-1)-\frac{1}{2} \sum_{j=1}^{m} t_{j}\left(t_{j}-1\right)\right]^{\frac{1}{2}}\left[\frac{1}{2} n(n-1)\right]^{\frac{1}{2}}
$$

The statistical $Z_{\mathrm{S}}$ test is often used to assess the importance of trends. Accordingly, if $Z_{\mathrm{s}}$ in equation (5) is positive, $Z_{\mathrm{S}}$ presents an upward trend while a negative presents a downward trend of the considered factor (Attogouinon et al., 2017; Joshi and Pandey, 2011). At significance level $\alpha, Z_{\mathrm{S}} \geq Z_{\alpha / 2}$, so the $\alpha$ trend of the data series, is considered to be significant.

To detect the monotonic trends of ERIs over the study area, three ERIs were assessed using the Mann-Kendall test and Sen's slope estimator with a significance level of $5.0 \%$. If the $p$-value is lower than this threshold level, $\mathrm{HO}$ is rejected. By rejecting the null 
assumption, the results record an upward or/downward trend if the $Z_{\mathrm{s}}$ value is positive or negative, respectively (Attogouinon et al., 2017; Su et al., 2006).

After monotonic trend is defined by the Mann-Kendall test, its magnitude is defined by Sen's slope estimator. Sen's slope is defined as follows:

$$
\beta=\operatorname{Median}\left(\frac{X_{i}-X_{j}}{i-j}\right) \text { with } j<i
$$

where $X_{i}, X_{j}$ are data series at time scales $t_{i}$ and $t_{j}$, respectively.

In this study, the Mann-Kendall test and Sen's slope estimator were used to detect the spatial and temporal variation of ERIs in the study area, with a significance level of $95 \%$. At a significance level of $5.0 \%$, the null hypothesis of no trend is rejected if $\left|Z_{S}\right|>1.96$.

Analysis of the ERIs' trends using the Mann-Kendall test and Sen's slope estimator, with a significance level of $95 \%$ was carried out to identify the possible temporal changes in rainfall frequency across the entire study area during the period 1984-2015.

\section{Results and discussion}

\subsection{Temporal features of extreme rainfall indices}

For the R20 index, 8 out of 12 stations recorded a downward trend (Figure 3). Specifically, slight downward trends were observed at western coastal stations, such as Kien Giang, Ca Mau, Hau Giang, Tien Giang and Can Tho, with $Z_{\mathrm{s}}$ values varying from -0.45 to -0.73 ; at the eastern coastal station, namely, Soc Trang $\left(Z_{\mathrm{s}}=-1.49\right)$; and at inland stations such as Vinh Long $\left(Z_{\mathrm{s}}=-0.24\right)$. A significant downward trend was recorded at Tra Vinh station $\left(Z_{\mathrm{s}}=-\right.$ 2.24) (Table 3). In contrast, a slight upward trend was recorded at stations such as An Giang, Dong Thap and Bac Lieu, with $Z_{\mathrm{s}}$ values ranging from 0.37 to 1.71 (Table 3 ).

Regarding the R50 index, with the exception of Soc Trang station, which detected no upward or downward trend, the entire study area recorded no significant changes in
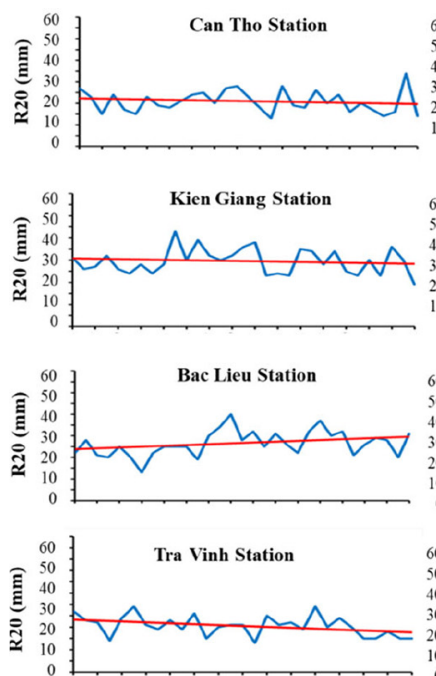

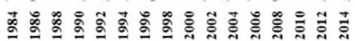
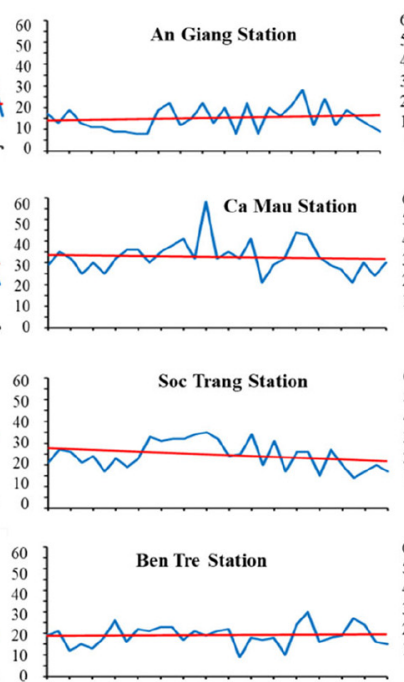

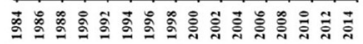
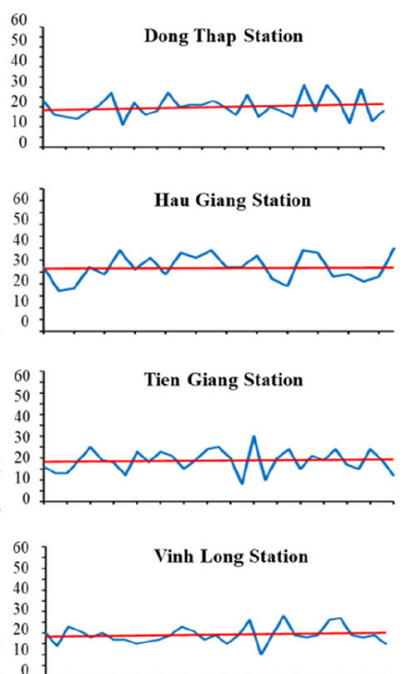

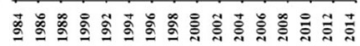

Extreme rainfall trends over the Mekong Delta 645 
IJCCSM

12,5

\section{6}

Figure 4.

Number of very heavy rainfall days during the period 1984-2015 tendency, while a slight upward trend was recorded at six out of 12 stations, including Ca Mau, Tra Vinh, Hau Giang, Vinh Long, Tien Giang and Dong Thap, with $Z_{\mathrm{s}}$ values from 0.11 to 1.56 (Table 4). In contrast, a slight downward trend was found at stations such as Kien Giang, Bac Lieu, Ben Tre, Can Tho and An Giang, with $Z_{\mathrm{s}}$ values ranging from -0.23 to -1.46 (Table 4).

Similarly, the analysed results for the R100 index are shown in Figure 5 and Table 5. Accordingly, a slight downward trend was recorded at western coastal stations such as Kien Giang and $\mathrm{Ca} \mathrm{Mau}$, with $Z_{\mathrm{S}}$ values varying from -0.41 to -0.82 ; at eastern coastal stations such as Tra Vinh and Ben Tre $\left(Z_{\mathrm{s}}=-0.58 \div-0.88\right)$; and at inland stations, namely, Can Tho, Hau Giang and Long An, with $Z_{\mathrm{s}}$ values ranging from -0.41 to -1.07 (Table 5). In contrast, a slight upward trend was recorded at Dong Thap, Vinh Long, Bac Lieu and Soc Trang
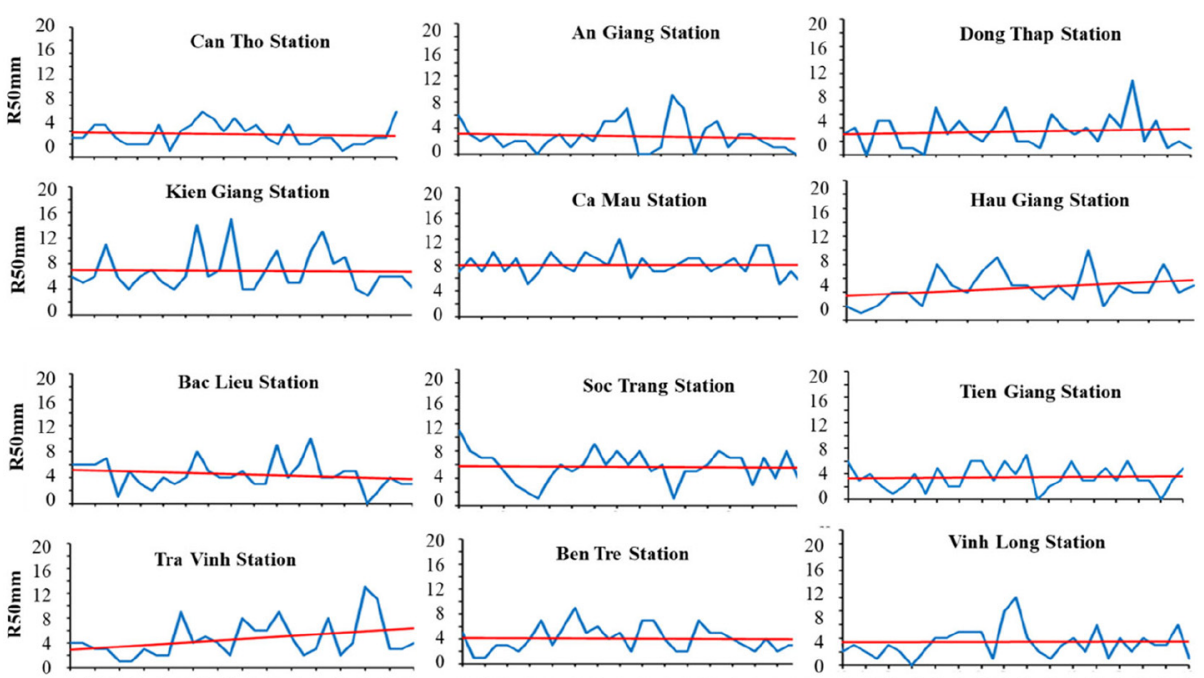

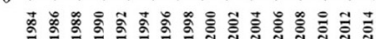

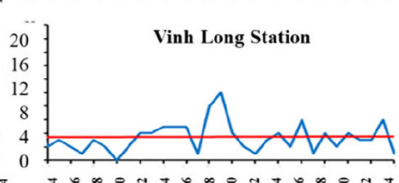

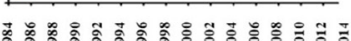

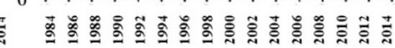

Table 3.

Statistical tests of heavy rainfall days during the period 1984-2015

\begin{tabular}{lccr}
\hline Station & $Z_{\mathrm{S}}$ & $p$-value & $\beta$ \\
\hline Kien Giang & -0.73 & 0.23 & -0.33 \\
Ca Mau & -0.49 & 0.31 & -0.28 \\
Bac Lieu & 1.71 & 0.04 & 0.00 \\
Soc Trang & -1.49 & 0.06 & -0.50 \\
Tra Vinh & -2.24 & 0.01 & -0.40 \\
Ben Tre & 0.00 & 0.50 & -0.20 \\
Can Tho & -0.63 & 0.10 & -0.33 \\
Hau Giang & -0.51 & 0.30 & -0.37 \\
Vinh Long & -0.24 & 0.40 & -0.08 \\
Tien Giang & -0.45 & 0.32 & -0.16 \\
Dong Thap & 0.58 & 0.27 & -0.15 \\
An Giang & 0.37 & 0.35 & -0.18 \\
\hline
\end{tabular}


stations $\left(Z_{\mathrm{s}}\right.$ varying from 0.02 to 1.35$)$. In particular, a significant upward trend was recorded at Tien Giang station $(\mathrm{Zs}=1.97)$, implying that the Tien Giang province faces a high risk of flooding problems compared to other regions.

\subsection{Spatial features of extreme rainfall indices}

The analysed results of the spatial pattern of ERIs across the study area in the period 1984-2015 are presented in Figures 6, 7 and 8. Figures 6-8 present the different symbols corresponding to the upward trend, no trend and the downward trend of the R20, R50 and R100, respectively, while different colour scales show the number of rainfall days of the R20, R50 and R100. The results show that the number of R20 days varied from 12 to 32 days per year (Figure 6). The highest number of R20 days, up to 30 days per year,

\begin{tabular}{lrcr}
\hline Station & \multicolumn{1}{c}{$Z_{\mathrm{S}}$} & $p$-value & \multicolumn{1}{c}{$\beta$} \\
\hline Kien Giang & -0.41 & 0.34 & -0.09 \\
Ca Mau & 0.11 & 0.45 & -0.07 \\
Bac Lieu & -1.46 & 0.07 & -0.11 \\
Soc Trang & 0.00 & 0.50 & -0.10 \\
Tra Vinh & 1.56 & 0.05 & 0.00 \\
Ben Tre & -0.23 & 0.40 & -0.08 \\
Can Tho & -0.84 & 0.19 & -0.09 \\
Hau Giang & 0.44 & 0.32 & -0.07 \\
Vinh Long & 0.32 & 0.37 & -0.06 \\
Tien Giang & 0.41 & 0.33 & -0.04 \\
Dong Thap & 0.11 & 0.45 & -0.07 \\
An Giang & -1.00 & 0.15 & -0.11 \\
\end{tabular}

Extreme rainfall trends over the Mekong Delta

\section{7}

Table 4. Statistical tests of very heavy rainfall days during the period 1984-2015
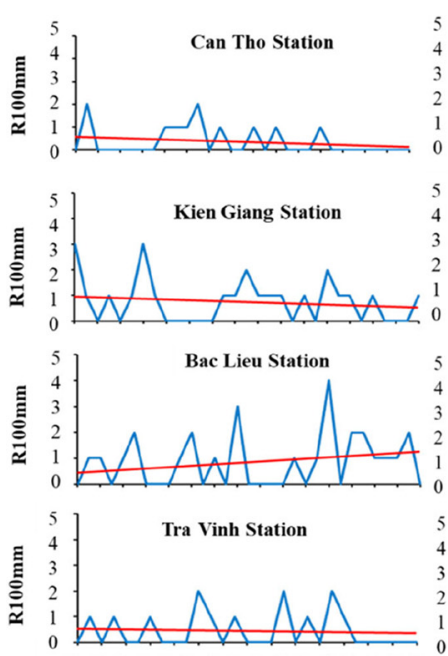

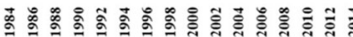
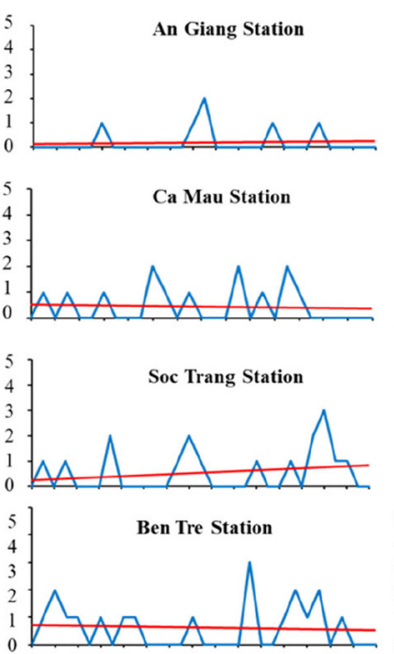
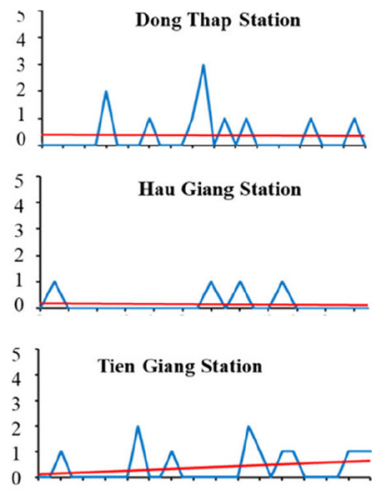

Vinh Long Station

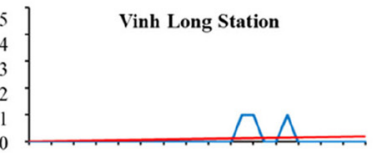

Figure 5. Number of daily maximum rainfall during the period 1984-2015 


\begin{tabular}{llcrr}
\cline { 2 - 5 } IJCCSM & Station & $Z_{\mathrm{S}}$ & $p$-value & \multicolumn{1}{c}{$\beta$} \\
\cline { 2 - 5 } 12,5 & Kien Giang & -0.41 & 0.34 & -0.05 \\
& Ca Mau & -0.82 & 0.20 & -0.08 \\
& Bac Lieu & 1.35 & 0.08 & 0.04 \\
& Soc Trang & 1.13 & 0.12 & 0.03 \\
$\mathbf{6 4 8}$ & Tra Vinh & -0.58 & 0.27 & 0.00 \\
& Ben Tre & -0.88 & 0.18 & -0.08 \\
& Can Tho & -1.07 & 0.14 & -0.09 \\
Table 5. & Hau Giang & -0.51 & 0.30 & -0.37 \\
Statistical tests of & Vinh Long & 1.16 & 0.12 & 0.03 \\
daily maximum & Dien Giang & 1.97 & 0.04 & 0.13 \\
rainfall during the & Long Thap & 0.02 & 0.29 & 0.00 \\
period 1984-2015 & An Giang & -0.53 & 0.33 & -0.01 \\
& & 0.41 & & 0.00 \\
\hline
\end{tabular}

Figure 6.

Spatial distribution of the number of heavy rainfall days in the period 1984-2015

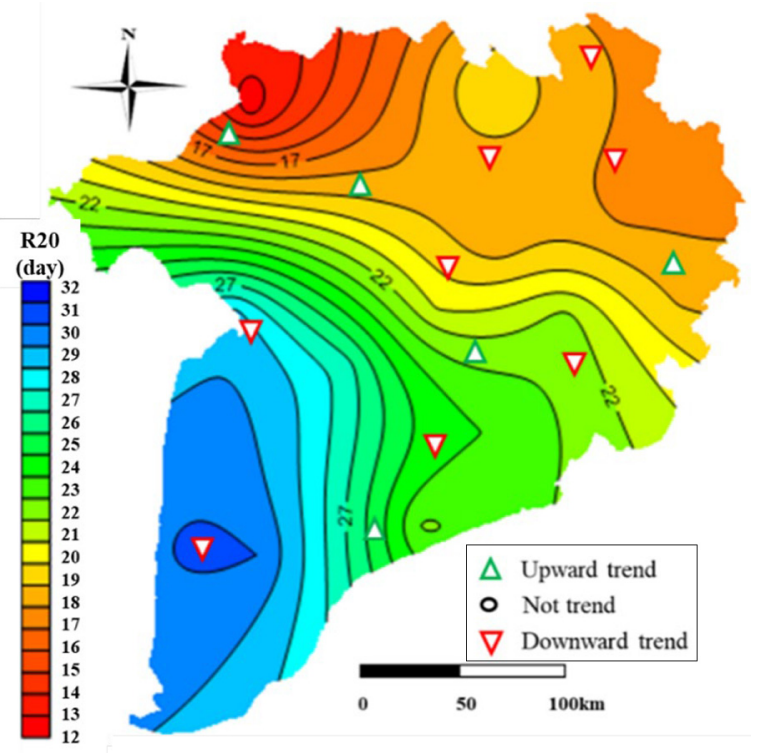

occurred in the western coastal regions (Kien Giang, Hau Giang and Ca Mau provinces). In contrast, the lowest number of the R20 index, 13 days per year, was recorded in the northern coastal regions, with a mean value approximately of 14 days per year. Specifically, for the spatial distribution of the R20 index, a shift and a slight upward trend were observed at the northern stations such as An Giang, Dong Thap, Tien Giang, Vinh Long and Bac Lieu, while a slight downward trend was recorded in all other regions. The statistical results also indicate that the number of R20 days decreased from the southern regions to the northern regions (Figure 6). In the study period (1984-2015), the highest number of 32 R20 days per year was observed at Ca Mau station, meaning that this region has a higher risk of heavy rainfall problems, leading to the inundation of planting crops. 


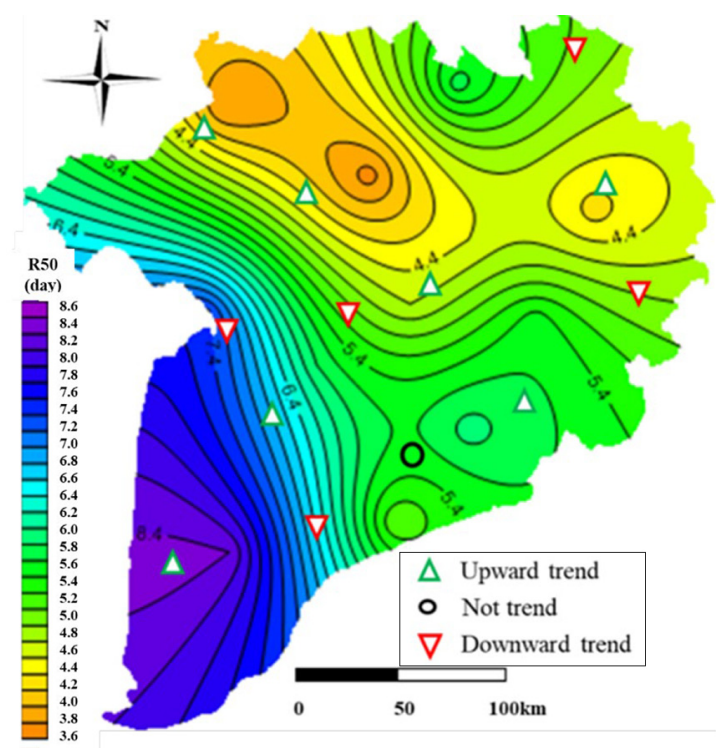

\section{Extreme rainfall trends over the Mekong Delta}

649

Figure 7.

Spatial distribution of the number of very heavy rainfall days in the period 1984-2015

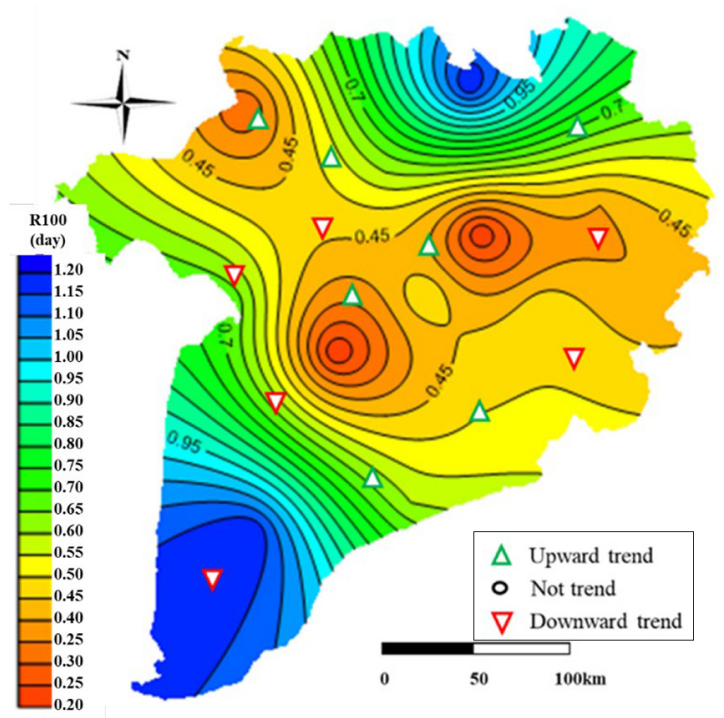

Figure 8.

Spatial distribution of the number of daily maximum rainfall in the period 1984-2015

Similarly, the spatial distribution of the R50 index is presented in Figure 7. The mean annual value of R50 over the entire study area was around six days per year. The highest values were recorded at the western coastal provinces such as Ca Mau, Kien Giang and Bac Lieu (7.2-8.6 days per year) and the lowest values occurred in the northern region (An Giang, Dong Thap Provinces) and eastern coastal region (Tien Giang and Long An Provinces), 
IJCCSM 12,5

varying between 3.6 and 4.6 days per year. From these results, it is possible to conclude that the flooding risk due to rainfall with high intensity in the southern coastal provinces is greater than in other regions.

Finally, the spatial distribution of the R100 index is displayed in Figure 8. The daily maximum rainfall in the period 1984-2015 fluctuated from 0.2 to 1.2 days per year; high values for R100 were recorded at Long An and Ca Mau provinces (up to 0.95 days per year), while low values of $\mathrm{R} 100$ were observed in most of the remaining regions.

Generally, the spatial distribution of the R100 index tends to shift from the eastern and western coastal provinces to inland provinces such as Long An and Dong Thap (Figure 8). It can be inferred that northwest provinces are facing a very high risk of maximum rainfall leading to heavy waterlogging and flooding compared to other regions.

\section{Conclusion}

This study analysed changing trends in ERIs using the Mann-Kendall test and Sen's slope estimator across the Mekong Delta, based on daily rainfall data series in the period 19842015. Regarding the R20 index, except for Tra Vinh station which recorded a significant downward trend, and Ben Tre station which did not record any upward or downward trend, eight out of the 12 stations belonging to the western and eastern coastal provinces recorded slight downward trends, while slight upward trends were observed at inland stations. Regarding spatial distribution, a slight shift of the R20 index was recorded from the southern to the northern provinces.

The absence of significant changes in the R50 index at Soc Trang station means no specific trends were detected. Slight upward/downward tendencies similar to the R20 index were observed for the R50 index, with six out of 12 stations recording slight upward trends and five out of 12 stations recording slight downward trends. The western coastal region, including Ca Mau, Kien Giang and, Bac Lieu provinces showed a high concentration of very heavy rainfall days.

Regarding the R100 index, a slight upward trend was observed at the eastern and, western coastal stations and at inland stations, while a slight upward trend occurred at Dong Thap, Vinh Long, Bac Lieu, Soc Trang stations. Notably, Tien Giang station recorded a significant upward trend in the R100 index, implying that a high risk of waterlogging threatens this region.

Overall, this study can improve the understanding of recent changes in the intensity and frequency of ERIs over the entire study area. The results of this study are extremely useful for supporting agricultural production and, aquaculture seafood and for minimising the damage caused by ERIs.

The results are also worth noting for the absence of a significant upward trend in the ERIs, which can be beneficial for agricultural production and aquaculture. However, in the long term, this will negatively impact the rainfall accumulation needed to provide irrigation water for planting crops in the dry season.

\section{References}

Adeniran, K.A., Amodu, M.F., Amodu, M.O. and Adeniji, F.A. (2010), "Water requirements of some selected crops in Kampe dam irrigation project", Australian Journal of Agricultural Engineering, Vol. 1 No. 4, pp. 119-125.

Asia-Pacific Network (2010), "Climate change in Southeast Asia and assessment on impact, vulnerability and adaptation on rice production and water resource", Project Reference Number: CRP2008-03CMY-Jintrawet. 
Attogouinon, A., Lawin, A.E., Po, Y.N.M. and Houngue, R. (2017), "Extreme rainfall indices trend assessment over the upper Oueme river valley (Benin)", Hydrology, Vol. 4 No. 3, p. 36, doi: 10.3390/hydrology4030036.

Chandler, R.E. and Scott, M.E. (2011), Statistical Methods for Trend Detection and Analysis in the Environmental Analysis, John Wiley and Sons, Chichester.

Croitoru, A.E., Chiotoroiu, B.C., Todorova, V.I. and Torica, V. (2013), "Changes in rainfall extremes on the black sea Western Coast", Global and Planetary Change, Vol. 102, pp. 10-19.

Daksiya, V., Mandapaka, P. and Edmond, Y.M.L. (2017), "A comparative frequency analysis of maximum daily rainfall for a SE Asian region under current and future climate conditions", Advances in Meteorology, Vol. 2017, available at: https://doi.org/10.1155/2017/2620798

Dang, T.A. (2019), "Analysis of maximum rainfall trends in the Long Xuyen quadrangle area over three past decades”, Transylvanian Review, Vol. 27 No. 42, pp. 10134-10139.

Dos Santos, C.A.C., Neale, C.M.U., Rao, T.V.R. and Da Silva, B.B. (2011), "Trends in indices for extremes in daily temperature and rainfall over Utah, USA", International Journal of Climatology, Vol. 31 No. 12, pp. 1813-1822.

Food and Agriculture Organization (FAO) (2016), "El Niño event in Viet Nam: agriculture, food security and livelihood need assessment in response to drought and saltwater intrusion", Assessment Report, p. 75.

Intergovernmental Panel on Climate Change (IPCC) (2012), "Managing the risks of extreme events and disasters to advance climate change adaptation", A special report of working groups I and II of the Intergovernmental Panel on Climate Change, Cambridge University Press: New York, NY.

Intergovernmental Panel on Climate Change (IPCC) (2014), "Climate change 2014: impacts, adaptation, and vulnerability", Part B: Regional Aspects. Contribution of Working Group II to the Fifth Assessment Report of the Intergovernmental Panel on 45 Climate Change, Cambridge University Press, Cambridge, New York, NY.

Jain, S.K. and Kumar, V. (2012), "Trend analysis of rainfall and temperature data for India", Current Science, Vol. 10 No. 1, pp. 37-49.

Joshi, M.K. and Pandey, A.C. (2011), "Trend and spectral analysis of rainfall over India during 19012000", Journal of Geophysical Research, Vol. 116 No. D6, available at: http://dx.doi.org/10.1029/ 2010JD014966

Lee, S.K. and Dang, T.A. (2018), "Predicting future water demand for Long Xuyen quadrangle under the impact of climate variability", Acta Geophysica, Vol. 66 No. 5, doi: 10.1007/s11600-018-0176-4.

Lee, S.K. and Dang, T.A. (2019a), "Spatio-temporal variations in meteorology drought over the Mekong river Delta of Vietnam in the recent decades", Paddy and Water Environment, Vol. 17 No. 1, doi: 10.1007/s10333-018-0681-8.

Lee, S.K. and Dang, T.A. (2019b), "Irrigation water requirement of rice in Long Xuyen quadrangle area, Vietnam in the context of climate change", Journal of Agrometeorology, Vol. 21 No. 1, pp. 18-23.

Lee, S.K. and Dang, T.A. (2019c), "Change trends of rainfall features for the Long Xuyen quadrangle, Vietnam”, Journal of Agrometeorology, Vol. 21 No. 3, pp. 382-384.

Lee, S.K. and Dang, T.A. (2019d), "Precipitation variability and trends over the Mekong Delta area of Vietnam”, Journal of Agrometeorology, Vol. 21 No. 2, pp. 217-219.

Liu, J., Doan, C.D., Liong, S., Sanders, R., Dao, A.T. and Fewtrell, T. (2015), "Regional frequency analysis of extreme rainfall events in Jakarta”, Natural Hazards, Vol. 75 No. 2, pp. 1075-1104.

Mekong Delta Plan (MDP) (2013), "Long-Term Vision and Strategy for a Safe, Prosperous and Sustainable Delta, Royal Haskoning DHV. Wageningen University, Deltares, Rebel, Netherlands.

Mondal, A. and Mujumdar, P.P. (2015), "Modeling non-stationarity in intensity, duration and frequency of extreme rainfall over India", Journal of Hydrology, Vol. 521, pp. 217-231. 
IJCCSM

12,5

Moulai, L.H., Mesbah, M., Gamane, D.S. and Medjerab, A. (2013), "Detecting hydro-climatic change using spatiotemporal analysis of rainfall time series in Western Algeria”, Natural Hazards, Vol. 65 No. 3, pp. 1293-1311.

Pingale, S.M., Khare, D., Jat, M.K. and Adamowski, J. (2014), "Spatial and temporal trends of mean and extreme rainfall and temperature for the 33 urban centers of the arid and semi-arid state of Rajasthan, India”, Atmospheric Research, Vol. 138 No. 1, pp. 73-90.

Singh, D., Tsiang, M., Rajaratnam, B. and Diffenbaugh, N.S. (2013), "Rainfall extremes over the continental United States in a transient, high-resolution, ensemble climate model experiment", Journal of Geophysical Research, Vol. 118, pp. 7063-7086.

Soro, G.E., Noufé, D., Bi, T.A.G. and Shorohou, B. (2016), "Trend analysis for extreme rainfall at Subdaily and daily timescales in Côte d'Ivoire", Climate, Vol. 4 No. 3, p. 37, doi: 10.3390/cli4030037.

Su, B.D., Jiang, T. and Jin, W.B. (2006), "Recent trends in observed temperature and precipitation extremes in the Yangtze River basin, China”, Theor Appl Climatol, Vol. 83 Nos 1/4, pp. 139-151, doi: 10.1007/s00704-005-0139-y.

Vu, D.T., Yamada, T. and Ishidaira, H. (2018), "Assessing the impact of sea level rise due to climate change on seawater intrusion in Mekong Delta, Vietnam", Water Science and Technology, doi: 10.2166/wst.2018.038.

Wani, J.M., Sarda, V.K. and Jain, S.K. (2013), “Assessment of trends and variability of rainfall and temperature for the district of mandi in Himachal Pradesh", Slovak Journal of Civil Engineering". , Vol. 25 No. 3, pp. 15-22.

Wu, F.T., Wang, S.Y., Fu, C.B., Qian, Y., Gao, Y., Lee, D.K., Cha, D.H., Tang, J.P. and Hong, S. (2016), "Evaluation and projection of summer extreme rainfall over East Asia in the regional model inter-comparison project", Climate Research, Vol. 69 No. 1, pp. 45-48.

Xu, Z.X., Yang, X.J., Zuo, D.P., Chu, Q. and Liu, W.F. (2015), "Spatiotemporal characteristics of extreme rainfall and temperature: a case study in Yunnan province, China", Proceedings of the International Association of Hydrological Sciences, Vol. 369, pp. 121-127, doi: 10.5194/piahs-369121-2015.

Yazid, M. and Humphries, U. (2007), "Regional observed trends in daily rainfall indices of extremes over the Indochina peninsula from 1960 to 2007”, Climate, Vol. 3 No. 1, pp. 168-192.

\section{Further reading}

Tramblay, Y., Badi, W., Driouech, F., El Adlouni, S., Neppel, L. and Servat, E. (2012), "Climate change impacts on extreme rainfall in Morocco", Glob Planet Change, Vols 82/83 No. 2, pp. 104-114.

\section{Corresponding author}

Lee Seung Kyu can be contacted at leeseungkyu@tdtu.edu.vn

For instructions on how to order reprints of this article, please visit our website: 